\title{
QUALITY OF CLOSE RELATIONSHIPS AND EMOTIONAL REGULATION REGARDING SOCIAL ANXIETY
}

\author{
Jasminka Juretić \\ University of Rijeka, Faculty of Humanities and Social Sciences, Department of Psychology, Rijeka, Croatia
}

received: 10.5.2017;

revised: 5.10.2017;

accepted: 15.11 .2017

\section{SUMMARY}

Background: The aim of this research is to propose new models in understanding the relationship between social anxiety and experiencing positive and negative emotions and satisfaction with life in general. Its main focus is to explore the roles of different types of close relationships in these models.

Subjects and methods: The sample consisted of 521 female students attending University of Rijeka and University of Pula (average age 21.21 years). The participants completed The Big Five Inventory, Beck Depression Inventory-II, Social Interaction Anxiety Scale, Social Phobia Scale, Emotion Regulation Questionnaire, Attitudes Towards Emotional Expression Questionnaire, Positive and Negative Affect Schedule - Expanded Form, Satisfaction with Life Scale, Quality of Relationship Inventory and Friendship Quality Questionnaire. The results were processed using the program LISREL 8.

Results: Two models have been tested. The first model includes the relationship between both types of social fears, beliefs about expressing emotions, emotional suppression, romantic relationship quality and the frequency of experiencing positive and negative emotions and life satisfaction. The second one included friendship quality, instead of romantic relationship quality. Both models are acceptable and draw out the powerful role of cognition in the aforementioned relations. This is achieved as a result of beliefs about the expression of emotions on other variables, and also confirms the mediatory role such beliefs have on social anxiety and emotional suppression. The models tested show the importance of the type of close relations we are following.

Conclusions: The contribution of this research lies in the point that it offers a more detailed insight into the complex relation between social anxiety and the experiencing of emotions, as well as the quality of life in general. This is achieved in the way that structural modeling has captured a part of the mediator mechanisms that have a role in this relation.

Key words: social anxiety - emotional regulation - friendship quality - romantic relationship quality

\section{INTRODUCTION}

Relationships with other people are an important source of our happiness and satisfaction, as well anxiety and fear. All people want social acceptance and intimacy, but socially anxious people develop beliefs and strategies that prevent them from achieving this (Alden \& Taylor 2004). Reduced intimacy can lead to reduced support in close relationships, and can increase loneliness and depression (Sparrevohn \& Rape 2009).

A series of studies have shown that social anxiety disorder impairs interpersonal relationships (Alden \& Taylor 2004, Kashdan \& Wenzel 2005, Leary \& Kowalski 1995, Wenzel 2009), and we can speak about "the general chronic interpersonal stress" of socially anxious individuals (Davila \& Beck 2002). Behaviors in choosing partners vary in the function of social anxiety (Wenzel \& Emerson 2009), and several studies have shown that the socially anxious are either more frequently unmarried (Furmark 2002) or marry later and have a greater likelihood to enter into marriage with their first partner (Caspi et al. 1988).

Social anxiety is also associated with different dimensions of friendship in childhood and adolescence (Kingery et al. 2010, La Greca \& Lopez 1998, La Greca \& Harrison, 2005), and social phobia is the only diagnosis that is associated with the perceived quality of friendship, above and beyond the perceived quality of family relationships (Rodebaugh 2009).

Socially anxious people experience emotional closeness and security with people from their social networks less frequently than those who are not socially anxious (Montgomery et al. 1991), and they display a variety of dysfunctional behaviors in their relationships with friends, family members and romantic partners (Beck \& Davilla 2003, Davila \& Beck 2002, Fernandez \& Rodebaugh 2011, Grant et al. 2007). They doubt their ability to achieve the desired impression on others, and therefore adopt subordinate, defensive and "harmless" behaviors that reduce the likelihood of rejection and rely on a conservative, low-risk self-presentation (Alden \& Bieling 1998, DePaulo et al. 1990, Hofmann \& Barlow 2004, Hofmann et al. 2004b, Leary \& Kowalski, 1995). The price of such an approach includes constant concern, which interferes with approaching behavior (such as seeking rewards and exploratory behavior) (Kashdan $\&$ Roberts 2007) and the establishment of a very delicate balance between the need for affiliation and the desire to avoid rejection (Kashdan \& Wenzel 2005).

Socially anxious people communicate at moderate levels of intimacy, regardless of the degree of self-disclosure of the person they are talking with (Leary \& Kowalski 1995). They resort to various security procedures or subtle avoidance (Clark \& Wells 1995, Leary 
\& Kowalski 1995, Rapee \& Heimberg 1997), which has implications on the development of close relationships. They believe that other people see them in a negative way after unpleasant social events and that these events are indicators of their negative traits. Such beliefs can lead to unpleasant consequences in long-term relationships and possibilities of achievement (Wilson \& Rape 2005). There are, however, results showing that there is some truth in the negative beliefs of the socially anxious about being less likeable than others, already at the first impression (Voncken \& Dijk 2013).

Although studies generally support the presence of an avoidant interaction style in socially anxious individuals, some suggest the presence of dependent style relationships with others (Darcy et al. 2005) and a different role of protective communication style in close relationships (Cuming \& Rapee 2010).

The regulation of emotions has an important role in understanding the quality of interpersonal relationships of socially anxious individuals. Problems in emotional regulation are significantly associated with symptoms of anxiety disorders (Cisler et al. 2010, Eftekhari et al. 2009). There is a connection between social anxiety disorder and deficits in emotional regulation ability (Eisner et al. 2009, Salovey et al. 2002). Suppression is one of the most widely studied emotion regulation strategies. Studies have shown that it is counterproductive because it actually leads to the paradoxical reinforcement of physiological arousal, and has a very adverse effect (Gross \& Levenson 1997, Hofmann et al. 2009, Lynch et al. 2001).

The strategy of emotional suppression is associated with the rare experience of positive emotions and infrequent expression (Gross \& John 2003, 2004, Richards \& Gross 2000). People who suppress emotions are less willing to share emotional, positive and negative, experiences with other people (Rime et al. 1992). Since close relationships involve strong emotions and encourage mutual disclosure, people who suppress emotions will not feel comfortable in such relationships and will actively try to avoid them (John \& Gross 2004). Emotional suppression is associated with a reduced quality of life and well-being, lower self-esteem and optimism (John \& Gross 2004).

People's beliefs about emotions and their own emotions' essentiality play an important role in the regulation of emotions (John \& Gross 2007). Some people believe that emotions are dangerous and harmful (Mennin et al. 2007), while others think of them as adaptable and changeable and more often modify their own emotions by changing the evaluation of events that caused them (Tamir et al. 2007). Socially anxious individuals believe that they will be less observable by others and, in the end, they will not be rejected if they restrain from showing emotions. They hold dysfunctional beliefs about emotional expression (Spokas et al. 2009). For them, it is very important to control emotional expression because the social consequence of rejection is a result of the expression of emotions. The socially anxious believe that showing emotions is a sign of weakness.
Recent research shows that a deficit in the expression of positive emotions is associated with social anxiety (Hughes et al. 2006, Kashdan 2002, 2004, 2007, Kashdan \& Steger 2006, Kashdan \& Breen 2008, Kashdan \& Collins 2010, Weeks et al. 2010). Socially anxious people compared to non-anxious people report a less frequent experience of daily positive emotions and positive events, and it cannot be attributed to the conceptual overlapping of social anxiety and other negative affective states (Kashdan \& Steger 2006). They express less positive emotions, even pay less attention to their own emotions and have more difficulty describing them (Turk et al. 2005).

Epidemiological studies have shown that consistently more women than men meet the criteria for social phobia (Furmark et al. 1999, Furmark 2002), so our research will focus on young women. The aim of this research is to propose new models in understanding the relationship between social anxiety and experiencing positive and negative emotions and satisfaction with life in general.

The proposed models are developed by integrating the Clark and Wells model of social phobia (1995) and the process model of emotion regulation (Gross 2001) with focus on variables that in certain way may mediate or moderate the relationships mentioned above. The main focus is to explore the roles of different types of close relationships in this models.

\section{SUBJECTS AND METHODS}

\section{Subjects}

The sample consisted of 521 female students attending the University of Rijeka and University of Pula. The average age of the participants was 21.21 ( $\mathrm{SD}=2.5$ years; range 18-37).

\section{Instruments}

To assess personality traits, The Big Five Inventory was used (John et al. 1991, source John \& Srivastava 1999). It provides a good coverage of all five personality traits (Extraversion, Agreeableness, Conscientiousness, Neuroticism and Openness), and has satisfactory psychometric properties. The inventory consists of 44 items, using a five-point Likert-type format for answer scoring. For the purposes of this study, only Neuroticism was assessed ( 8 items). The Cronbach-alpha for the present sample was .81 .

The Beck Depression Inventory-II (BDI-II; Beck et al. 1996) has been used to assess depressive symptoms. It is a 21-item self-report scale, using a four-point Likert-type format (a higher number meaning more severe depressive symptom). The Cronbach-alpha in this sample was 0.90 .

Anxiety in social interaction was assessed using the Social Interaction Anxiety Scale (SIAS; Mattick \& Clarke 1998) and the fear of being observed and evaluated by others is measured by the Social Phobia Scale (SPS; Mattick \& Clarke 1998). Both self-report 
scales consist of 20 items each, using a five-point Likert-type format for scoring the answers. The Cronbach-alpha for SIAS was 0.90 and for SPS 0.91.

The Emotion Regulation Questionnaire (ERQ; Gross \& John 2003) was used to assess emotional regulation strategies - reappraisal and suppression. For the purposes of this study only the Suppression subscale is used. It consists of 4 items measuring the tendency to inhibit or conceal the emotional expression that a person has experienced. Answers are scored by using a sevenpoint Likert-type format. The internal reliability coefficient (Cronbach-alpha) for this subscale on the sample of participants of the present study is 0.74 .

Attitudes Towards Emotional Expression Questionnaire (ATEEQ; Joseph \& al. 1994) measures negative beliefs and behaviors related to emotional expression, and in the present study it is used to assess beliefs about emotional expression. It is a 20 -item self-report scale, using a five-point Likert-type format for answer scoring. In the original form, the questionnaire consists of four factors: beliefs about meaning (a sign of weakness), beliefs about expression (keep under control), beliefs about consequences (social rejection) and behavioral style (bottling up). The present study did not confirm these four subscales, but the authors recommended that subsequent research should focus on subscales as well as the overall scale. In the present study, two factors were extracted, each of them with 10 items. The first factor is composed of items that in the original questionnaire are related to beliefs that expressing emotions is a sign of weakness, and beliefs that expressing emotions leads to social rejection. This factor is, therefore, called the belief that expressing emotions leads to unpleasant consequences. The second factor is composed of items that in the original structure of the questionnaire are related to the belief that it is important to have the expression of emotions under control and of items related to the behavioral tendency to suppress the expression of emotion. This factor is called the belief that emotions should not be expressed. Cronbach-alpha for both subscales was 0.87 .

To measure the subjective experience of emotion, the Positive and Negative Affect Schedule - Expanded Form (PANAS - X; Watson \& Clark 1994) has been used. This is a 20 -item inventory that consists of 10 adjectives measuring positive affect (e.g. cheerful) and 10 adjectives measuring negative affect (e.g. irritable). Answers are scored by using a five-point Likert-type format. The Cronbach-alpha for positive affect subscale was .85 and for negative affect subscale 0.87 .

In order to assess to what extent a person is satisfied with her life, a Satisfaction with Life Scale (SWLS; Diener et al. 1985) has been used. It is a 5-item selfreport scale, using the seven-point Likert-type format for answers scoring. The Cronbach-alpha in the present sample was 0.86 .

The quality of the romantic relationship has been assessed by the Quality of Relationship Inventory (QRI; Pierce et al. 1991). This is a 25 -item self-report inven- tory, using a five-point Likert-type format for answer scoring. In the original form, the QRI consists of three components of a particular relationship: social support, conflict and depth. These three factors have not been confirmed in the present study. Instead, two factors were extracted. The first factor involves items related to conflict in a particular romantic relationship and the second one resulted as an item combination of subscales social support and depth of relationship. For the purpose of this study, only the second factor (11 items) has been used and it has been called romantic relationship quality. The Cronbach-alpha for this factor was 0.83 .

The Friendship Quality Questionnaire (FQQ; Parker $\&$ Asher 1993) has been used to assess the quality of the relationship with best friends. For the purpose of this study, it is adapted to the student population. The FQQ is a 40-item self-report scale, using a five-point Likerttype format for scoring the answers. In the original form, the questionnaire consists of six factors which measure different aspects of friendship. The present study did not confirm these six subscales and three factor structures emerged. Items which measure companionship, recreation and the instrumental support that a best friend provides, create the first factor. The second factor consists of items related to conflict present in a particular relationship, and the third one refers to loyalty, intimate exchange and mutual respect. This last factor (14 items) was the only one used for the purpose of the present study and is called friendship quality. The Cronbach-alpha for this subscale was 0.89 .

\section{Procedure}

Data was collected anonymously during classes using paper-pen testing. The goal of the study was briefly explained and students participated voluntarily. Students who were not willing to participate were allowed to leave the room.

\section{RESULTS}

In order to determine the relationship between the variables involved in the study, correlation analyzes have been performed. Pearson's correlation coefficients are shown in Table 1.

All of the correlation coefficients are significant. Both social fears and beliefs about emotional expression are positively correlated to emotional suppression and negative emotions, and negatively correlated with the perceived quality of romantic relationships and friendships, experiencing positive emotions and life satisfaction. Asides from these correlations, emotional suppression is positively correlated and romantic relationships and friendship quality are negatively correlated to negative emotions. The more frequent experiencing of positive emotions means the reduced experiencing of negative emotions and greater life satisfaction, while frequently experiencing negative emotions means lower life satisfaction in general. 
Table 1. Correlations between variables involved in the proposed model

\begin{tabular}{cccccccccc}
\hline & 1 & 2 & 3 & 4 & 5 & 6 & 7 & 8 & 9 \\
\hline 0 & $0.74^{* *}$ & $0.45^{* *}$ & $0.29^{* *}$ & $0.28^{* *}$ & $-0.28^{* *}$ & $-0.24^{* *}$ & $-0.30^{* *}$ & $0.52^{* *}$ & $-0.40^{* *}$ \\
1 & - & $0.41^{* *}$ & $0.21^{* *}$ & $0.18^{* *}$ & $-0.27^{* *}$ & $-0.16^{* *}$ & $-0.21^{* *}$ & $0.53^{* *}$ & $-0.38^{* *}$ \\
2 & & - & $0.64^{* *}$ & $0.48^{* *}$ & $-0.37^{* *}$ & $-0.35^{* *}$ & $-0.15^{* *}$ & $0.39^{* *}$ & $-0.31^{* *}$ \\
3 & & & - & $0.75^{* *}$ & $-0.26^{* *}$ & $-0.21^{* *}$ & $-0.14^{* *}$ & $0.14^{* *}$ & $-0.18^{* *}$ \\
4 & & & & - & $-0.23^{* *}$ & $-0.20^{* *}$ & $-0.15^{* *}$ & $0.12^{* *}$ & $-0.19^{* *}$ \\
5 & & & & & - & $0.32^{* *}$ & $0.18^{* *}$ & $-0.31^{* *}$ & $0.33^{* *}$ \\
6 & & & & & & - & $0.27^{* *}$ & $-0.20^{* *}$ & $0.20^{* *}$ \\
7 & & & & & & & - & $-0.17^{* *}$ & $0.43^{* *}$ \\
8 & & & & & & & & - & $-0.43^{* *}$ \\
\hline
\end{tabular}

Variables: 1: Fear of being evaluated by others; 2: Belief - expressing emotions leads to unpleasant consequences;

3: Belief - emotions should not be expressed;

6: Friendship quality; 7: Positive emotions;

0 : Anxiety in social interactions;

4: Emotional suppression; $\quad 5$ : Romantic relationship quality;

8: Negative emotions;

$* * \mathrm{p}<0.01$
In order to determine the unique relationship between social anxiety and other variables in further analyses, a common variance of social anxiety shared with neuroticism and depression is controlled. The aim was to eliminate the possibility that the potential negative effects of social anxiety, primarily in experiencing positive emotions, can be attributed to a common variance, or negative affectivity, which is shared by social anxiety, neuroticism and depression, and not to the uniqueness of social anxiety. Certain models suggest that neuroticism as a higher common vulnerability factor explains most of the covariance among the more specific constructs such as social anxiety, depression and anger (Kashdan 2002). It is considered that there are unique characteristics of high social anxiety that are not part of neuroticism. In order to control neuroticism and depression, regression analyses were performed with standardized residuals calculated for both types of social fears. In this way we got two new variables, which were used for further analysis and in which negative affectivity related to neuroticism and depression is excluded, and only the part that is associated with a particular social fear has remained.

A variety of statistical analyzes were conducted in order to answer the research questions. The results were processed using the program LISREL 8 (Jöreskog \& Sörbom 2002).

Two models have been tested. The first model has included the relationship between both types of social fears, beliefs about expressing emotions, emotional suppression, romantic relationship quality and the frequency of experiencing positive and negative emotions and life satisfaction. This theoretical model is shown in Figure 1. Only significant direct and indirect effects are shown. Model fit indexes for this model are shown in Table 2.

The indexes shown in Table 2. indicate that this model is acceptable. The Chi-square index is significant, but it is affected by sample size and for large samples is generally significant. To reduce the sensitivity of the model chi-square to sample size, the ratio of the chisquare and degrees of freedom have been calculated.
This ratio indicates that the model is acceptable. GFI, NFI and CFI show a good fit of this model with empirical data. RMSEA value suggests reasonable error of approximation.

The model has revealed that both types of social fears influence relationships with other variables. Anxiety in social interactions has direct positive effects on the belief that expressing emotions leads to unpleasant consequences (0.33) and on negative emotions (0.27). In relation to other variables, this type of social fear has been achieved indirectly through the belief that emotions should not be expressed, emotional suppression and the quality of romantic relationships. The fear of being evaluated by others has created only a direct, positive, weak but significant effect on life satisfaction (0.12). The belief that expressing emotions leads to unpleasant consequences has a direct, positive and high impact on the belief that emotions should not be expressed (0.64), which has a direct, high and positive effect on the suppression of emotions (0.73). The suppression of emotions and belief that emotional expression leads to unpleasant consequences have direct and negative effects on the quality of partnerships (-0.17, -0.24 ). The quality of romantic relationships has a direct effect on positive emotions (0.15), negative emotions $(-0.22)$ and life satisfaction (0.14). Negative emotions have a direct negative effects on positive emotions $(-0.29)$ and life satisfaction (-0.36). Positive emotions generate a direct positive effect on life satisfaction (0.37).

According to the data obtained for this model, its main feature is strong relations of beliefs about emotional expression and emotional suppression, through which the relationship of anxiety in social interactions and other variables is achieved.

The second model tested included the relationship between both types of social fears, beliefs about expressing emotions, emotional suppression, friendship quality and frequency of experiencing positive and negative emotions and life satisfaction. This theoretical model is shown in Figure 2. Only significant direct and indirect effects are shown. Model fit indexes for this model are shown in Table 3. 


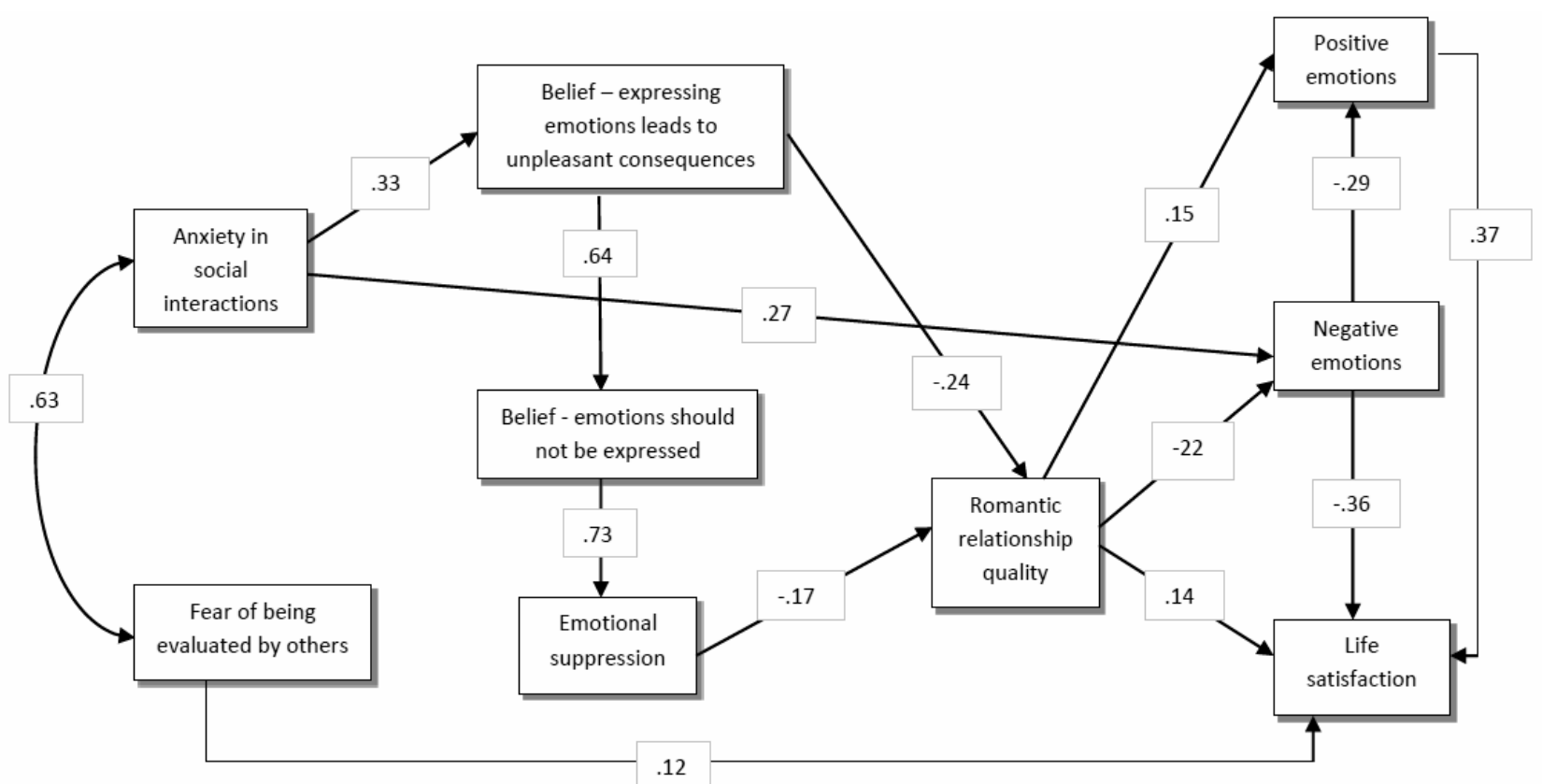

Figure 1. The model of relations between social anxiety, beliefs about the expression of emotions, emotional suppression, romantic relationship quality, positive and negative emotions and life satisfaction

Table 2. Fit indexes for theoretical model compared with empirical data

\begin{tabular}{cccccccc}
\hline & $\chi^{2}$ & degrees of freedom & $\chi^{2} /$ degrees of freedom & RMSEA & GFI & NFI & CFI \\
\hline Model & $43.62^{* *}$ & 22 & 1.98 & 0.06 & 0.96 & 0.94 & 0.97 \\
\hline$* * \mathrm{p}<0.01$ & & & & & & &
\end{tabular}

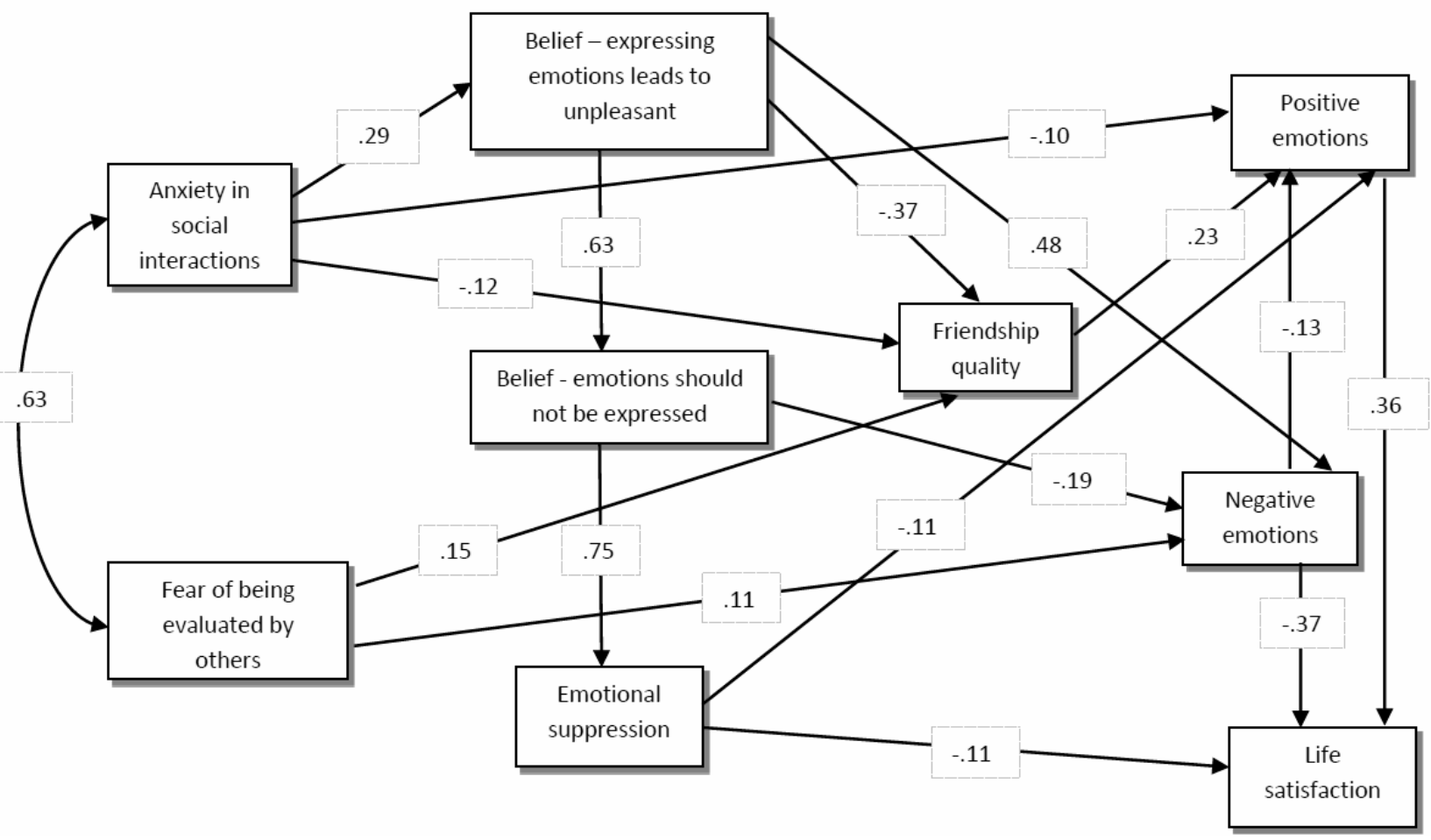

Figure 2. The model of relations between social anxiety, beliefs about the expression of emotions, emotional suppression, friendship quality, positive and negative emotions and life satisfaction

Table 3. Fit indexes for theoretical model compared with empirical data

\begin{tabular}{cccccccc}
\hline & $\chi^{2}$ & degrees of freedom & $\chi^{2} /$ degrees of freedom & RMSEA & GFI & NFI & CFI \\
\hline Model & 14.01 & 18 & 0.78 & 0.00 & 0.99 & 0.99 & 1.00 \\
\hline
\end{tabular}


This model fits very well with the empirical data for all the accounted for parameters.

Both types of social fears have effects on other variables. Anxiety in social interactions has a direct positive effect on the belief that expressing emotions leads to unpleasant consequences (0.29), the direct negative effects on the friendship quality $(-0.12)$ and the frequency of experiencing positive emotions (-0.10). As with the previous model, the other effects are achieved indirectly. The fear of being evaluated by others has a direct positive impact on the friendship quality (0.15) and the frequency of experiencing negative emotions (0.11). The belief that expressing emotions leads to unpleasant consequences, as with the previous model, shows a direct, positive and high impact on the belief that emotions should not be expressed (0.63). Its direct, positive and moderate effect on negative emotions (0.48), and direct negative impact on friendship quality $(-0.37)$ is also shown. The belief that emotions should not be expressed has shown a direct, high and positive effect on emotional suppression (0.75) and a direct negative effect on negative emotions (-0.19). The suppression of emotions has a direct negative effects on positive emotions $(-0.11)$ and life satisfaction (-0.11). Only friendship quality has achieved a direct positive effect on positive emotions (0.23) which makes a direct positive impact on life satisfaction (0.36). Negative emotions have direct negative effects on positive emotions (-0.13) and life satisfaction $(-0.37)$.

The results have shown that the effects of variables generated in this model are more complex than the previous ones. Both types of social fears achieve direct and indirect effects on other variables. As with the previous model, this model shows strong relations of beliefs about emotional expression and emotional suppression.

\section{DISCUSSION}

The testing in the first model examined the relations between social anxiety, beliefs about the expression of emotions, emotional suppression, romantic relationship quality, as well as the experience of positve and negative emotions and overall life quality.

The model shows that both social fears create significant direct and indirect effects on other variables included in the model. Anxiety in social interactions has direct positive effects on the belief that expressing emotions leads to unpleasant consequences and negative emotions. In terms of this aspect of social anxiety, it was also expected that it would have direct effects on the belief that emotions should not be expressed and on the suppression of emotions. These effects are not confirmed and relations to those variables are indirectly created through the belief that expressing emotions leads to unpleasant consequences. Coefficients of effects of these variables are quite high and positive.
This kind of relationship could mean that women with higher social anxiety traits will be more prone to suppress emotions if they have strong beliefs that expressing emotions leads to unpleasant consequences. Due to this, the belief that emotions should not be expressed will also be activated and women with a higher level of social anxiety would choose emotional suppression as an emotional regulation strategy. These results suggest the importance of our beliefs in the emotional regulation process.

The cognitive model (Clark \& Wells 1995) assumes that when a person finds herself or himself in a particular social context, negative assumptions (concerning the assessment of the situation as dangerous) are activated. With that image in mind, a series of negative automatic thoughts about themselves and other people are also activated. The mediatory role of beliefs about emotional expression in the relationship between social anxiety and emotional suppression emphasizes the role of cognition in this relationship. It seems that the belief that expressing emotions leads to unpleasant consequences is "superior" to the belief that emotions should not be expressed. Unpleasant consequences might refer to the belief that expressing emotions is a sign of weakness, meaning that someone who expresses emotions openly (in particular negative emotions) is labeled as a weak person. Evaluating a person as weak means a certain character trait or defect since it is considered that the adult must be able to successfully and adequately regulate their own emotional expression. People who can control their own emotions are perceived as strong, so someone who is not able to do this could be seen to be weak and possibly less desirable as friends and partners.

Although, in the first instance, a person's fear that they will be evaluated and perceived as weak is related to the regulation of emotions, to a certain extent, a parallel can be made with Moscovitch'es work (2008) about the foundational fears that socially phobic people experience. According to the model the author mentions, a socially phobic person is fearful that in the eyes of other people their character, and in fact their whole self, will be seen as inadequate in comparison to other people, and this will result in the particular consequences that she/he is afraid of. If we put this in the context of what we are discussing here, the belief that the expression of emotions will result in unpleasant effects clearly leads to the non-expression of emotions and, in the end, to their suppression. Socially anxious women use this way of regulating their emotions in order to reduce the possibility of experiencing any uncomfortable consequences. The strategy is in fact paradoxical because the suppression of emotions is contra-productive concerning the desire to reduce unwanted, uncomfortable experiences and physical arousal (Aldao et al. 2010, Gross 1998, Gross 2001, Gross \& John 2003, Hofmann \& al. 2009, John \& Gross 2004, Richards \& Gross 2000). 
The confirmed negative effect that the suppression of emotions has on the quality of romantic partner relations is visible in the results of other research (John $\&$ Gross 2004). The suppression of emotions reduces levels of intimacy with partners, as well as their support (Gross 2002, Gross et al. 2006). This result is in accordance with data that shows that socially anxious people develop specific ways of interpersonal communication, which in coupled with an absence of assertiveness, conflict avoidance and increased dependence on partners, includes the avoidance of emotional expression (Davila \& Beck 2002).

There are in existence, however, results that show an adaptive function to the suppression of emotions in romantic partner relations. They show that socially anxious women maintain their romantic relations by suppressing the expression of negative feelings, thoughts, images and physical sensations. This is supported by research that confirms the determined benefits that are a result of the strategy of emotional suppression (Kashdan et al. 2007).

The aspect of social anxiety which relates to the fear of others people's judgements creates a significant direct and positive effect on life satisfaction. This means that socially anxious women who fear the judgement of other people actually live a more satisfactory life, which is not in accordance with expectations. It is possible that those women adopt nonassertive submissive strategies of functioning, trying to avoid any form of conflict and this makes them more satisfied in life. All direct interaction with a conversant is a possible occasion for negative judgment, which is what they fear, so the avoidance of such situations is a strategy to maintain existing life satisfaction.

The results also confirm the expectation that romantic relationship quality results in the more frequent experience of positive emotions rather than negative ones, and that a girl who forms better quality partner relations will be more satisfied with her own life. The results given from this model show that she will more often experience positive emotions, and more rarely negative ones, which means increased life satisfaction. The model is also given that a young women who experiences negative emotions more frequently will also more rarely experience positive ones.

The next model wanted to confirm the relation between social anxiety, beliefs about expressing emotions, emotional suppression, the quality of friendships, as well as experiencing positive and negative emotions and the quality of life. First of all, this model showed to be in thorough accordance with the empirical results, which means that it explains the previously mentioned relations very well, even though this is the most complex to explain.

The fear of other people's judgements creates a direct positive effect on the quality of friendships, as well as the experience of negative emotions. This means that women who experience this fear have better quality friendships and also experience negative emotions more frequently. A possible reason as to why this type of social anxiety has a positive effect on the quality of friendships is that due to the fear of other people's judgments, which includes friends, socially anxious women develop specific strategies and behaviors which maintain good quality friendships. Research has shown that some socially anxious people interact with other people in a "non-threatening" way, which includes polite laughter, approval, increased positive nodding of the head, and also they more frequently explain themselves and apologize (Hofmann et al. 2004a). It is possible that socially anxious women are actually more prone to this kind of behavior with their best friends, although it possibly concerns their highest quality interpersonal relation. However, their fear of unacceptance and rejection is so strong that this kind of behavior is the "price they pay" to maintain the existing relation. Since they experience negative emotions more often, this is a possible indicator of the additional price they pay due to their increased fear of judgement and rejection by other people.

The fear of the other people's judgments has an indirect effect on the experience of positive emotions through the friendship quality, and on life satisfaction through the experience of negative emotions.

This model, as well as the previous one, confirms the powerful role of the belief that the expression of emotions leads to unpleasant experiences. Experiencing anxiety in social interactions creates a direct effect exactly on this type of belief, and this then goes on to create a direct effect on the belief that emotions should not be expressed, which then leads to the suppression of emotions. This type of social fear also creates a direct effect on positive emotions and on the quality of friendship. Young women for whom this fear is more expressed less frequently experience positive emotions and have less good quality friendships. This finding is in accordance with previous research that connects social anxiety (in the first instance this type of social fear) with a less frequent experience of positive emotions, as well as less good quality partner relations (e.g. Kashdan 2007, Sparrevohn \& Rapee 2009).

This type of social fear indirectly creates a relation with negative emotions through the belief that the expression of emotions leads to unpleasant consequences, and this in turn creates a direct positive effect on the belief that emotions should not be expressed. The belief that emotions should not be expressed directly creates a negative effect on negative emotions. This means that women who strongly believe that emotions should not be expressed less frequently experience negative emotions. Such a finding is in contradiction with the role of this belief (that the expression of emotions causes uncomfortable consequences) on negative emotions, because women who believe this go on to more frequently experience negative emotions. The effect of both beliefs on emotional suppression is created directly and indirectly, but it shows that the suppression of emo- 
tions neither creates a direct or indirect effect on the frequency of experiencing negative emotions. It could be said that in a way there is a "break" in the relation between the belief and the suppression of negative emotions. On the one hand, beliefs about the expression of emotions create the opposite effect on negative emotions. More frequently experienced negative emotions, with the explicit belief that the expression of emotions leads to uncomfortable results, can be in accordance with that research that shows that irrespective of whether negative emotions are suppressed or not, their subjective experience is not reduced (Gross 1998).

However, when following the role of the belief that emotions should not be expressed, it becomes apparent that negative emotions are experienced less often and this is not in accordance with what has been previously stated. At the same time, it does not result in their suppression so the expected connection of this type of belief with negative emotions is not created. When examining this model, we should consider the emotional reactivity of the participant and most certainly include it as a measure in future research. This result suggests weaker emotional reactivity, and reduced experiencing of emotions, and thus there is no need for emotional suppression.

A less frequent experience of negative emotions reduces the need to suppress emotional experience. Further research should consider which negative emotions are involved in research when examining their expression or suppression. Since this research only concerns data given from women, it is possible that the culture in which we live has a specific effect. Although there exists a clearly expressed belief that emotions should not be expressed, it is possible that the effect of this belief is not the same for different negative emotions. For example, it is socially acceptable for women to express sadness but not anger. It is possible that in the relation between beliefs about expressing emotions and the experience of negative emotions some other mechanisms concerning the cognitive control of emotions are included.

The results of the tested model show that the suppression of emotions in young women will result in the less frequent experience of positive emotions, as well as reduced life satisfaction. This is in accordance with previous research that has confirmed the relation between the emotional suppression and the rarer experience of positive emotions, as well as their rarer expression (Gross \& John 2003, John \& Gross 2004, Richards \& Gross 2000). The connection between emotional suppression as a strategy of emotional regulation with reduced life satisfaction is also confirmed (Gross \& John 2003).

However, what is more interesting is the result that does not show that emotional suppression has a significant effect on the quality of friendship. A possible reason for this might be that friendships are more stable and long term than the romantic relations that are estimated $(\mathrm{M}=28.84$ months; $\mathrm{SD}=32.32)$. Romantic relations are an important part of everyday life for the life of students and the majority of students consider their romantic partner to be the closest relation they have, which Demir's (2008) research also confirms. The effect of emotional suppression is shown as important in this type of relation, whereby socially anxious women believe that the suppression of emotions will improve and maybe maintain good quality partner relations. It is possible that in friendships women are freer to express their emotions because they are not so worried about whether they will be rejected or negatively judged, and friendships for this age group are more stable, and generally longer lasting than romantic relations. Thus, expectations of intimacy, and social and emotional support are greater in friendships than in partner relations. Since it is shown that the belief that the expression of emotions leads to unpleasant consequences has a significant role on the friendship quality, those women who believe this less will have better quality friendships.

At the same time, the results have shown that the belief that emotions should not be expressed and about emotional suppression has no effect on the friendship quality. This opens up the possibility that in contrast to romantic partner relations, more emotions are expressed in friendship relations.

A direct positive effect has been demonstrated of the quality of the friendship on the frequency of experiencing positive emotions. Socially anxious women who have better quality friendships, experience positive emotions more frequently. More frequently experienced negative emotions leads to a rarer experience of positive emotions, as well as a reduced life satisfaction, whilst the more frequent experience of positive emotions shows greater life satisfaction. This finding is in accordance with the results of the model which included romantic partner relations as well as data already previously explained.

When following the results given from this research, it is important to take a number of limitations into account.

In the first instance, this is research that is based on data resulting from participants' self-assessments. In order to better capture the problems this research has focused on, and to find a better way to examine the aforementioned relations, and considering that the research has showed different ways of regulating emotions during lab experiments and in everyday conditions, it would be better to carry out this type of research in everyday conditions of the functioning of socially anxious people. (e.g. Kashdan et al. 2013).

A further limitation is that only women participated in this research, and this an appropriate sample of participants. Due to gender differences in the expression of social anxiety and the way emotions are regulated, in future research it would be useful to see what results would be given by a sample of men and compare the models given by both genders. Research on a clinical sample of socially anxious women whose condition reduces everyday functioning might give different results. 
In future research, it would also be good to check individual differences in emotional reactions when following the relations that are examined here, and also emotional knowledge. This is because results have shown that social anxiety is associated with reduced emotional knowledge (O'Toole et al. 2013). Furthermore, it would be important to check what results would be given by examining the aforementioned relations for repeated cognitive estimation as a strategy of emotional regulation. This strategy is shown as adaptive, and our data shows the importance of cognition in the relation between social anxiety and the suppression of emotions. At the same time, this research covered the area of the quality of close relations and has shown that strategies of emotional regulation have different effects on memory, and through memory on contents that are connected to interpersonal relations and the quality of close relations (Gross 2002, Richards \& Gross 2000).

It is also worth mentioning the practical contribution of this research. Considering the powerful role of the dysfunctional belief that the expression of emotions will create uncomfortable effects, which goes on to activate the belief that emotions should not be expressed, in therapeutic work it is especially important to work on restructuring this type of belief that relates to the dangers of emotions and their expression. On the other hand, the expression of emotion is important for the development of interpersonal relations. It is important for individuals to learn adaptive strategies to regulate emotions and show the advantages and benefits, as well as disadvantages, of using different strategies. However, such strategies of regulating emotions are only a part of an entire system of self-regulation, and it would be useful to explore what capacities a person has for self-regulation in general.

The contribution of this research lies in the point that it offers a more detailed insight into the complex relation between social anxiety and the experiencing of emotions, as well as the quality of life in general. It does this in a way whereby structural modeling has captured a part of the mediator mechanisms that have a role in this relation. A review of available literature shows that up until now there is no research that connects the aforementioned variables in this way.

\section{CONCLUSIONS}

Generally speaking, when explaining the relations between social anxiety, beliefs about expressing emotions, emotional suppression, quality of close relationships and experiencing emotions, as well as life satisfaction in general, both models draw out the powerful role of cognition in the aforementioned relations. This is achieved through beliefs about the expression of emotions on other variables, and also confirms the mediatory role such beliefs have in relation to social anxiety and emotional suppression (Spokas et al. 2009). The models tested show the importance of the type of close relations we are following, which in this case are romantic partner relations and friendships.

\section{Acknowledgements: None.}

\section{Conflict of interest: None to declare.}

\section{References}

1. Aldao A, Nolen-Hoeksema $S$ \& Schweizer S: Emotion regulation strategies and psychopathology: A meta analysis. Clin Psychol Rev 2010; 30:217-237

2. Alden LE \& Bieling P: Interpersonal consequences of the pursuit of safety. Behav Res Ther 1998; 36:53-64

3. Alden LE \& Taylor CT: Interpersonal processes in social phobia. Clin Psychol Rev 2004; 24:857-882

4. Beck AT, Steer RA \& Brown GK: Beck Depression Inventory - Second Edition (BDI-II) Manual. Harcourt Brace \& Company, San Antonio, 1996

5. Beck JG \& Davila J: Development of an interview for anxiety-relevant interpersonal styles: Preliminary support for convergent and discriminant validity. J Psychopatol Behav 2003; 25:1-9

6. Caspi A, Elder GH \& Bem DJ: Moving Away From the World: Life-Course Patterns of Shy Children. Dev Psychol 1988; 24: 824-831

7. Cisler JM, Olatunji BO, Feldner MT \& Forsyth JP. Emotion Regulation and the Anxiety Disorders: An Integrative Review. J Psychopathol Behav Assess 2010; 32: 68-82

8. Clark DM \& Wells A: A Cognitive Model of Social Phobia. In: Heimberg RG, Liebowitz MR, Hope DA \& Schneier FR (eds.): Social Phobia: Diagnosis, Assessment, and Tretment, 69-94. The Guilford Press, 1995

9. Cuming $S \&$ Rapee RM: Social anxiety and self-protective communication style in close relationships. Behav Res Ther 2010; 48: 87-96

10. Darcy K, Davila J \& Beck JG: Is Social Anxiety Associated With Both Interpersonal Avoidance and Interpersonal Dependence? Cognitive Ther Res 2005; 29: 171-186

11. Davila J \& Beck JG: Is Social Anxiety Associated With Impairment in Close Relationships? A Preliminary Investigation. Behav Ther 2002; 33: 427-446

12. Demir M: Sweetheart, you really make me happy: romantic relationship quality and personality as predictors of happiness among emerging adults. Happiness Stud 2008; 9:257-277

13. DePaulo BM, Epstein JA \& Steele LeMay C: Responses of the socially anxious to the prospect of interpersonal evaluation. J Pers 1990; 58: 623-640

14. Diener E, Emmons RA, Larsen RJ \& Griffin S: The Satisfaction With Life Scale. J Pers Assess 1985; 49:71-75

15. Eftekhari A, Zoellner LA \& Vigil S: Patterns of emotion regulation and psychopathology. Anxiety Stress Copin 2009; 22: 571-586

16. Eisner LR, Johnson SL \& Carver CS: Positive affect regulation in anxiety disorders. J Anxiety Disord 2009; 23: $645-649$

17. Fernandez, KC \& Rodebaugh, TL: Social anxiety and discomfort with friendly giving. J Anxeiety Disord 2011; 25: $326-334$

18. Furmark, T: Social phobia: overview of community surveys. Acta Psychiat Scand 2002; 105: 84-93

19. Furmark T, Tillfors M, Everz P, Marteinsdottir I, Gefvert $O \&$ Fredrikson M: Social phobia in the general 
population: prevalence and sociodemographic profile. Soc Psych Psych Epid 1999; 34: 416-24

20. Grant DM, Beck JG, Farrow SM \& Davila J: Do interpersonal features of social anxiety influence the development of depressive symptoms? Cognition Emotion 2007; 21:646-663

21. Gross JJ: Antecedent- and Response-Focused Emotion Regulation: Divergent Consequences for Experience, Expression, and Physiology. J Pers Soc Psychol 1998; 74: 224-237

22. Gross JJ: Emotion Regulation in Adulthood: Timing Is Everything. Curr Dir Psychol Sci 2001; 10: 214-219

23. Gross JJ: Emotion regulation: Affective, cognitive, and social consequences. Psychophysiology 2002; 39:281-291

24. Gross JJ \& John OP: Individual Differences in Two Emotion Regulation Processes: Implications for Affect, Relationships, and Well-Being. J Pers Soc Psychol 2003; 85: 348-362

25. Gross JJ \& Levenson RW: Hiding Feelings: The Acute Effects of Inhibiting Negative and Posititive Emotion. $J$ Abnorm Psycho 1997:106, 95-103

26. Gross JJ, Richards JM, John OP: Emotion Regulation in Everyday Life. In Snyder DK, Simpson J \& Hughes JN (eds): Emotion regulation in couples and families: Pathways to dysfunction and health, 13-35. American Psychological Association, Washington, DC, 2006

27. Hofmann GS \& Barlow DH: Social Phobia (Social Anxiety Disorder). In Barlow DH (eds): Anxiety and Its Disorders: The Nature and treatment of anxiety and Panic, 454-477. The Guilford Press, 2004

28. Hofmann SG, Heering S, Sawyer AT \& Asnaani A: How to handle anxiety: The effects of reappraisal, acceptance, and suppression strategies on anxious arousal. Behav Res Ther 2009; 47: 389-394

29. Hofmann SG, Heinrichs $N \&$ Moscovitch DA: The nature and expression of social phobia: Toward a new classification. Clin Psychol Rev 2004a; 24: 769-797

30. Hofmann SG, Moscovitch DA \& Heinrichs $N$ : Evolutionary mechanisms of fear and anxiety. In: Gilbert $P(e d)$ : Evolutionary theory and cognitive therapy, 119137. Springer Publishing, $2004 \mathrm{~b}$

31. Hughes AA, Heimberg RG, Coles ME, Gibb BE, Liebowitz $M R$ \& Schneier FR: Relations of the factors of the tripartite model of anxiety and depression to types of social anxiety. Behav Res Ther 2006; 44: 1629-1641

32. John OP \& Gross JJ: Healthy and Unhealthy Emotion Regulation: Personality Processes, Individual Differences, and Life Span Development. J Pers 2004; 72: 1301-1334

33. John OP \& Gross JJ: Individual Differences in Emotional regulation. In Gross JJ (ed.): Handbook of Emotion Regulation, 351-373. The Guilford Press, 2007

34. John OP \& Srivastava S: The Big Five trait taxonomy: History, measurement, and theoretical perspectives. In Pervin LA \& John OP (eds.): Handbook of personality: Theory and research, 102-139. The Guilford Press, 1999

35. Jöreskog $K$ \& Sörbom D: LISREL 8.53. Scientific Software International, Inc., Chicago, 2002

36. Joseph $S$, Williams $R$, Irwing $P$ \& Cammock $T$ : The preliminary development of measure to assess attitudes towards emotional expression. Pers Individ Dif 1994; 16 : 869-875

37. Kashdan TB: Social anxiety dimensions, neuroticism, and the contours of positive psychological functioning. Cognitive Ther Res 2002; 26: 789-810
38. Kashdan TB: The neglected relationship between social interaction anxiety and hedonic deficits: Differentiation from depressive symptoms. J Anxiety Disord 2004; 18:719-730

39. Kashdan TB: Social anxiety spectrum and diminished positive experiences: Theoretical synthesis and metaanalysis. Clin Psychol Rev 2007; 27:348-365

40. Kashdan TB \& Breen WE: Social Anxiety and Positive Emotions: A Prospective Examination of a Self-Regulatory Model With Tendencies to Suppress or Express Emotions as a Moderating Variable. Behav Ther 2008; 39: 1-12

41. Kashdan TB \& Collins RL: Social anxiety and the experience of positive emotions and anger in everyday life: An ecological momentary assessment approach. Anxiety Stress Copin 2010; 23:259-272

42. Kashdan TB, Farmer AS, Adams LM, Ferssizidis $P$, McKnight PE \& Nezlek JB: Distinguishing Healthy Adults From People With Social Anxiety Disorder: Evidence for the Value of Experiential Avoidance and Positive Emotions in Everyday Social Interactions. J Abnorm Psychol 2013; 122: 645-655

43. Kashdan TB \& Roberts JE: Social anxiety, depressive symptoms, and post-event rumination: Affective consequences and social contextual influences. J Anxiety Disord 2007; 21:284-301

44. Kashdan TB \& Steger M: Expanding topography of social anxiety: An experience sampling assessment of positive emotions and events, and emotion suppression. Psychol Sci 2006; 17: 120-128

45. Kashdan TB \& Wenzel A: A Transactional Approach to Social Anxiety and the Genesis of Interpersonal Closeness: Self, Partner, and Social Context. Behav Ther 2005; 36: 335-346

46. Kashdan TB, Volkmann J, Breen WE \& Han S: Social anxiety and romantic relationships: The costs and benefits of negative emotion expression are context-dependent. $J$ Anxiety Disord 2007; 21: 475-492

47. Kingery JN, Erdley CA, Marshall KC, Whitaker $K G$ \& Reuter TR: Peer experiences of anxious and socially withdrawn youth: An integrative review of the developmental and clinical literature. Clin Child Fam Psychol Rev 2010; 13: 91-128

48. La Greca AM \& Lopez N: Social Anxiety Among Adolescents: Linkages with Peer Relations and Friendships. J Abnorm Child Psych 1998; 26: 83-94

49. La Greca AM \& Harrison HW: Adolescent peer relations, Friendships and romantic relationships: Do they predict social anxiety and depression? J Clin Child Adolesc Psychol 2005;34, 49-61

50. Leary MR \& Kowalski RM: Social Anxiety. The Guilford Press, New York, 1995

51. Lynch TA, Robins CJ, Morse JO \& Krause ED: A mediational model relating affect intensity, emotional inhibition, and psychological distress. Behav Ther 2001; 32:519-536

52. Mattick RP \& Clarke JC: Development and validation of measures of social phobia scrutiny fear and social interaction anxiety. Behav Res Ther 1998; 36, 455-470

53. Mennin DS, Holaway RM, Fresco DM, Moore MT \& Heimberg RG: Delineating Components of Emotion and its Dysregulation in Anxiety and Mood Psychopathology. Behav Ther 2007; 38, 284-302

54. Montgomery RL, Haemmerlie FM \& Edwards M: Social, personal, and interpersonal deficits in socially anxious people. J Soc Behav Pers, 1991; 6: 859-872 
55. Moscovitch DA: What Is the Core Fear in Social Phobia? A New Model to Facilitate Individualized case Conceptualization and Tretment. Cogn Behav Pract 2008; 16:123-134

56. O'Toole MS, Hougaarda E \& Mennin DS: Social anxiety and emotion knowledge: A meta-analysis. $J$ Anxiety Disord 2013; 27:98-108

57. Parker JG \& Asher SR: Friendship and Friendship Quality in Middle Childhood: Links With Peer Group Acceptance and Feelings of Loneliness and Social Dissatisfaction. Dev Psychol 1993; 29:611-621

58. Pierce GR, Sarason IG \& Sarason BR: General and Relationship-Based Perceptions of Social Support: Are Two Constructs Better Then One? J Pers Soc Psychol 1991; 61: 1028-1039

59. Rapee $R M$ \& Heimberg RG: A cognitive-behavioral model of anxiety in social phobia. Behav Res Ther 1997; 35:741-756

60. Richards JM \& Gross JJ: Emotion Regulation and Memory: The Cognitive Costs of Keeping One's Cool. J Pers Soc Psychol 2000; 79: 410-424

61. Rimé B, Philippot P, Boca $S$ \& Mesquita B: Long-lasting Cognitive and Social Consequences of Emotion: Social Sharing and Rumination. Eur Rev Soc Psychol 1992; 3: 225-258

62. Rodebaugh TL: Social phobia and perceived quality of friendship. J Anxiety Disord 2009; 23: 872-878

63. Salovey P, Stroud LR, Woolery A \& Epel ES: Perceived emotional intelligence, stress reactivity, and symptom reports: Further explorations using the Trait Meta-Mood Scale. Psychol Health 2002; 17:611-627

64. Sparrevohn RM \& Rapee RM: Self-disclosure, emotional expression and intimacy within romantic relationships of people with social phobia. Behav Res Ther 2009; 47:1074-1078

65. Spokas M, Luterek JA \& Heimberg RG: Social anxiety and emotional suppression: The mediating role of beliefs. $J$ Behav Ther Exp Psychiatry 2009; 40: 283-291

66. Tamir M, John OP, Srivastava $S$ \& Gross JJ: Implicit Theories of Emotion: Affective and Social Outcomes Across a Major Life Transition. J Pers Soc Psychol 2007; 92: 731-744

67. Turk CL, Heimberg RG, Luterek JA, Mennin DS \& Fresco DM: Delineating emotion regulation deficits in generalized anxiety disorder: A comparison with social anxiety disorder. Cognitive Ther Res 2005; 29: 89-106

68. Voncken MJ \& Dijk KFL: Socially Anxious Individuals Get a Second Chance After Being Disliked at First Sight: The Role of Self-Disclosure in the Development of Likeability in Sequential Social Contact. Cognit Ther Res 2013; 37:7-17

69. Watson D \& Clark LA: The PANAS-X: Manual for the Positive and Negative Affect Schedule - Expanded Form. University of Iowa: Psychology Publications, 1994

70. Weeks JW, Jakatdar TA \& Heimberg RG: Comparing and contrasting fears of positive and negative evaluation as facets of social anxiety. J Soc Clin Psychol 2010; 29:68-94

71. Wenzel A: Social anxiety. In: Reis HL \& Sprecher S (Eds.): Encyclopedia of human relationships, 1514-1517. Sage Publications, 2009

72. Wenzel A \& Emerson T: Mate selection in socially anxious and nonanxious individuals. J Soc Clin Psychol 2009; 28:341-363

73. Wilson JK \& Rapee RM: The interpretation of negative social events in social phobia with versus without comorbid mood disorder. J Anxiety Disord 2005; 19:245-274

Correspondence:

Ass. Prof. Jasminka Juretić, $M D, P h D$

University of Rijeka, Faculty of Humanities and Social Sciences, Department of Psychology

Sveučilišna avenija 4, HR-51000 Rijeka, Croatia

E-mail: jasminka2@ffri.hr 